\title{
LA EFICACIA DE LA EXCEPCIÓN DE CONTRATO NO CUMPLIDO FRENTE AL INCUMPLIMIENTO DE CONTRATOS VINCULADOS EN EL ÁMBITO DEL CONSUMO. ANÁLISIS SOBRE SU EJERCICIO EN PROCESOS DE EJECUCIÓN*
}

\section{SEBASTIÁN BOZZO HAURI**}

RESUMEN: El estudio de la contratación vinculada en el ámbito de consumo y la eficacia de la excepción de incumplimiento contractual en esta esfera exige, a nuestro juicio, detenernos en el análisis de este medio de defensa cuando se opone en procedimientos de ejecución. Así, el presente trabajo en una primera parte se refiere en modo general a la figura de la excepción de contrato no cumplido y de la contratación vinculada, explicando su noción y presupuestos. Posteriormente, se ofrece un análisis sobre la oposición de la exceptio en el juicio ejecutivo y, en especial, cuando se ejercita por el consumidor en el contexto de la contratación vinculada. Finalmente, se aborda el estudio de la exceptio non adimpleti contractus en el juicio ejecutivo de cobro de letras, pagarés y cheques, como también el de facturas.

PALABRAS CLAVE: Excepción de contrato no cumplido; Contratos vinculados; Incumplimiento; Juicio ejecutivo; Letra, Pagaré, Cheques y Facturas.

Fecha de recepción: 6 de septiembre de 2016.

Fecha de aceptación: 1 de febrero de 2017.

Este trabajo forma parte del Proyecto Fondecyt Postdoctoral N ${ }^{\circ} 3150272$, titulado "Contrato no cumplido y sus efectos en el contrato vinculado: Adquisición de bienes y servicios por parte del consumidor y el contrato para su financiamiento".

** Doctor en Derecho Universidad de Valencia, Máster Derecho de la Empresa Universidad de Valencia. Profesor de Derecho Civil Universidad Autónoma de Chile (Chile). Correo electrónico: sebastian.bozzo@uautonoma.cl 


\title{
THE EFFICACY OF THE EXCEPTION OF A BREACH OF CONTRACT AGAINST THE BREACH OF CONTRACT BONDS IN THE SPHERE OF CONSUMPTION. ANALYSIS OF THEIR EXCERCISE IN EXECUTORY PROCESSES
}

\begin{abstract}
In our view, the study of contract bonds and the efficacy of the exception of a breach of contract in the sphere of consumption requires focusing on the analysis of this means of defense when it opposes to executory processes. Thus, the present study in its first part is basically related to the figure of the exception of a breach of contract and the contract bond, as well as the corresponding explanation of its concept and conditions. Subsequently, an analysis about the opposition of the exceptio in the executory process is provided, in particular, when it is exercised by the consumer in the context of the contract bond. Lastly, the study of the exceptio non adimpleti contractus in the executory process of collecting installments, promissory notes, checks and bills is approached.
\end{abstract}

KEY WORDS: Exception of a breach of contract; Contract bonds; Breach; Executory process; Installment; Promissory note; Checks and Bills.

Sumario: Introducción. 1) Precisiones previas sobre la excepción de contrato no cumplido y contratos vinculados. (1.1.) Excepción de contrato no cumplido. (1.1.1.) Presupuestos de la excepción de incumplimiento contractual. (1.2.) Contratos vinculados. (1.2.1.) Noción de contratos vinculados. (1.2.2.) Presupuestos de los contratos vinculados. 2) Ejercicio de la exceptio en procedimientos de ejecución. (2.1.) Oposición de la exceptio en el juicio ejecutivo. (2.2.) Ejercicio de la exceptio en un procedimiento de ejecución ante el incumplimiento de contratos vinculados. 3) El ejercicio de la exceptio respecto de otros juicios de ejecución. (3.1.) Cobro ejecutivo de letras, pagaré y cheques. (3.2.) Cobro ejecutivo de facturas. Conclusiones. Bibliografía citada. Jurisprudencia citada.

\section{INTRODUCCIÓN}

La celebración de contratos conexos o vinculados se caracteriza por el hecho de que varios sujetos celebran dos o más contratos que presentan una estrecha relación funcional entre sí, por razón de su propia naturaleza 
o de la finalidad global que los informa, vinculación que es o puede ser jurídicamente relevante ${ }^{1}$. La funcionalidad en el caso que indicamos estaría dada normalmente gracias al nexo existente entre la compraventa del bien o servicio y el prestamo de dinero. Dicha interrelación entre ambos acuerdos permite que el primero, es decir la compraventa, pueda desarrollarse o cumplir su función y, por otra parte, la empresa que financia puede aumentar su cuota de mercado al existir un acuerdo previo que facilita el progreso del negocio de este último ${ }^{2}$.

La situación descrita se despliega con un propósito claro: desarrollar un negocio con mayor fluidez, permitiendo al consumidor obtener el crédito de una manera rápida y sencilla. De esta forma, por lo general, es el propio vendedor del bien o servicio quien facilita el crédito, actuando en representación del tercero, que es quien financia directamente la operación comercial. El fenómeno no es menor, ya que a diario se producen contrataciones con el carácter de coligadas o imbricadas entre sí, en la búsqueda de una finalidad común, situación que nos aleja velozmente del contrato concebido por los Códigos decimonónicos: ya no es posible estudiarlo como figura "aislada", porque se ha "ensanchado" su contenido, se han expandido sus moldes, y ello exige el examen de este desde su nueva realidad ${ }^{3}$.

La figura descrita tiene importantes beneficios para las partes que celebran este tipo de negocio, no es menos cierto que en caso de incumplimiento del vendedor, ello deja al consumidor desprotegido. Esto es así, ya que al haber celebrado dos contratos diferentes y con distintos sujetos, el consumidor debería en principio seguir cumpliendo con las cuotas del crédito, aunque el vendedor incumpla total o parcialmente el contrato de consumo.

En caso de aceptar la teoría de los contratos vinculados que ya hemos defendido en otro trabajo ${ }^{4}$, la excepción de contrato no cumplido sería un medio de defensa para el consumidor ante el incumplimiento del vendedor, para impedir que quien otorgó el crédito exija el cumplimien-

López Frí́s, Ana (1994) Los contratos conexos. Barcelona: Bosch, p. 36.

Messineo, Francesco (1952) Doctrina general del contrato. Buenos Aires: Ediciones Jurídicas Europa-América, p. 85, indica que: "Los contratos vinculados constituyen algo más amplio que la mera reciprocidad y que esa vinculación puede ser tanto genética como funcional".

3 Segui, Adela (2001) Teoría de los contratos conexos. Alguna de sus aplicaciones, en Instituciones de Derecho Privado - Contratación Contemporánea, dirigida por Alterini, Atilio Aníbal; De Los Mozos, José Luis; Sото, Carlos Alberto (editores), Bogotá: Editorial Temis S.A., t. II, 2001. "El contrato ha 'renunciado' a su aislamiento: no es habitual que se presente solo, sino vinculado a otros contratos, formando redes, 'paquetes' de productos y servicios, surgiendo la noción de 'operación económica', que se vale de varios contratos como instrumentos para su realización, lo que nos lleva al estudio de las 'redes contractuales'”.

4 Ver Bozzo, Sebastián (2015) "Incumplimiento de contratos vinculados en función de consumo y mecanismos de protección en el ordenamiento chileno". Revista de Derecho de la Pontificia Universidad Católica de Valparaíso, No 45, pp. 39-66. 
to del prestamo, todo esto con la particularidad de que la excepción se opone al prestamista por el incumplimiento del vendedor. Esto obligaría, entre otras cosas, a dejar atrás, como tradicionalmente se ha entendido, el principio del efecto relativo de los contratos, que consagra la idea de que "solo las partes que han concurrido a su celebración resultan obligadas" 5 . De esta manera, bajo determinadas condiciones, la nulidad o resolución de uno de los contratos del conjunto puede significar la ineficacia de los actos jurídicos que participan de él. En este sentido, si aceptamos lo anterior, el principio del efecto relativo de los contratos se vería lesionado.

$\mathrm{Si}$ asumimos que la teoría de los contratos vinculados en el ámbito de consumo podría tener aplicación en nuestro sistema, y siendo, por ende, posible admitir el ejercicio de la excepción de inejecución, resulta justificado su análisis cuando el prestamista inicia el cobro del crédito a través de un juicio ejecutivo. La situación es compleja, ya que -como sabemos- las opciones de defensa del deudor en este tipo de juicios son bastante limitadas.

\section{1) PRECISIONES PREVIAS SOBRE LA EXCEPCIÓN DE CONTRATO NO CUMPLIDO Y CONTRATOS VINCULADOS}

\section{(1.1.) EXCEPCIÓN DE CONTRATO NO CUMPLIDO}

El remedio sinalagmático por excelencia es la acción resolutoria, figura que tiene por objetivo primordial resolver el contrato, desvinculando a las partes de la relación obligatoria en la que se encontraban inmersas ${ }^{6}$. Escondida en el ordenamiento jurídico se encuentra la exceptio non adimpleti contractus, institución reconocida a nivel doctrinal como jurisprudencial. No obstante, y a diferencia de la resolución, no existe al respecto una regulación expresa en nuestro sistema ${ }^{7}$, debiendo colegirse de diferentes normas, entre otras, la del artículo 1.552 del Código Civil ${ }^{8}$.

5 Claro Solar, Luis (1937) Explicaciones de Derecho Civil Chileno y Comparado. Santiago de Chile: Imprenta Nascimento, t. II, De las obligaciones, p. 468; Aвeliuk, René (1993) Las Obligaciones. Santiago de Chile: Editorial Jurídica de Chile, p. 105.

6 Dírz-Picazo, Luis (1996) Fundamentos del Derecho Civil Patrimonial. Madrid: Editorial Civitas, vol. II, p. 722.

7 Sobre la no existencia de una regulación expresa de la exceptio ver Mejías Alonzo, Claudia (2013). "La excepción de contrato no cumplido y su consagración en el código civil chileno". Revista Chilena de Derecho, vol. 40, N² 2, p. 389.

8 Caprile, Bruno (2012) "Algunos problemas ofrecidos por la excepción de contrato no cumplido y, en especial, el de su invocación para atajar la acción resolutoria en el caso de in- 
Del estudio de los contratos bilaterales y de las obligaciones recíprocas y especialmente de los específicos efectos que produce este tipo de obligaciones, es posible llegar al análisis de la excepción de contrato no cumplido9 . Estos efectos determinados son una consecuencia del principio de interdependencia o reciprocidad que nace del contrato bilateral y se pueden resumir en los siguientes:

i. Cada parte puede rechazar el cumplimiento de su obligación, mientras la otra no cumpla la suya, sin por ello incurrir en mora.

ii. Cada parte puede pedir la resolución del contrato, si la otra no cumple con su obligación, o su ejecución forzosa y, en ambos casos, además la responsabilidad por el daño producido derivado del incumplimiento.

iii. Finalmente, si una de las partes no ha cumplido su obligación por causa que no le es imputable, la otra no debe tampoco cumplir la suya, siendo liberada de su obligación ${ }^{10}$.

Estos tres importantes efectos tienen como punto de conexión el principio de interdependencia, y es en la consagración a nivel de la doctrina de este principio donde encuentra sus bases la exceptio.

El cumplimiento simultáneo es uno de los efectos fundamentales de las obligaciones recíprocas o sinalagmáticas ${ }^{11}$, deduciéndose de diferen-

cumplimiento recíproco de los contratantes". Revista de Derecho de la Pontificia Universidad Católica de Valparaíso, No 39, pp. 53 y ss.

$9 \quad$ En este sentido, el Tribunal Supremo español indica que "A su vez, el contrato bilateral produce efectos peculiares, como consecuencia del vínculo de reciprocidad que liga a las respectivas prestaciones de las partes, pues cada una de ellas se obliga con el fin de obtener el cumplimiento de la obligación de la otra, lo que da lugar a las siguientes particularidades: a) Cumplimiento simultáneo de las obligaciones recíprocas, de cuya exigencia se deriva la imposibilidad de incurrir en mora una parte mientras la otra no cumpla, y el no poder exigir una de las partes el cumplimiento de su obligación a la otra, sin haber cumplido por su parte la suya ('exceptio non adimpleti contractus'); b) la posibilidad de resolver el contrato cuando uno de los contratantes incumple su obligación, liberándose la parte cumplidora del vínculo mediante la acción resolutoria, o exigir el cumplimiento de la obligación, con el resarcimiento de daños y abono de intereses en ambos casos (artículo 1.124 del Código Civil)". Tribunal Supremo Español. 4 de abril de 2011. ROJ STS 2015/2011. Disponible en: www.poderjudicial.es/search [fecha de visita: 1 de septiembre de 2016].

10 Se debe considerar como excepción a lo indicado que en las obligaciones de dar en especie se aplica el principio de que el riesgo es del acreedor conforme los artículos 1.550 y 1.820 de nuestro Código Civil, por lo que el acreedor en estos casos no quedará liberado de la prestación en caso de pérdida de la cosa debida por caso fortuito o fuerza mayor.

11 Ogayar y Ayllón, Tomás (1983) Efectos que produce la obligación bilateral: Doctrina jurisprudencial sobre los artículos 1124 y 1504 del Código Civil. Pamplona: Editorial Aranzadi, p. 33; y Colin, Ambrosio y Capitant, Henri (1924) Curso elemental de derecho civil. Traducción de la última edición francesa por la Redacción de la Revista General de Legislación y Jurisprudencia, con anotaciones al Derecho Civil español por De Buen, tomo III, Madrid: Editorial 
tes disposiciones legales (artículos 1.552, 1.826 y 1.872 del C.C.), debe siempre respetarse, salvo que las partes hayan establecido el cumplimiento diferido o por la naturaleza del contrato o la ley se establezca otra cosa diferente.

Por ello, en las obligaciones recíprocas, en el caso de que uno de los exigidos no cumpliese lo que le incumbe, al perjudicado se le reconoce una facultad establecida en el artículo 1.489 C.C. y que consiste en el derecho de exigir el cumplimiento o la resolución de la obligación, con derecho siempre a ser indemnizado por daños. Al mismo tiempo, fundado en el principio de cumplimiento simultáneo que rige para la ejecución de las obligaciones recíprocas, el demandado podrá negarse a la pretensión contraria, mientras la parte adversa no cumpla su prestación previa o no ofrezca su cumplimiento.

La exceptio non adimpleti contractus es, en este sentido, un remedio de carácter defensivo que se concede al deudor de una obligación recíproca para que pueda negarse legítimamente a la ejecución de la prestación por él debida, en tanto no se cumpla u ofrezca cumplir la prestación que se le debe ${ }^{12}$. Es, además, una compensación menor, en el sentido de que si se ofrece la posibilidad de exigir la resolución del contrato o la ejecución forzosa de la prestación, es lógico que se permita optar a detener el propio cumplimiento hasta que no se cumpla u ofrezca el cumplimiento por la contraparte ${ }^{13}$.

Cabe mencionar que se distinguen dos tipos de excepciones: la genuina excepción de incumplimiento contractual, que se produce frente a

Reus, p. 678, se señala respecto de la simultaneidad lo siguiente: "Pero si los contratantes no han determinado el orden de cumplimiento de sus obligaciones, este cumplimiento debe ser recíproco y simultáneo. Esta simultaneidad es, en efecto, conforme a la naturaleza misma del contrato sinalagmático. Cada contratante, como solo consiente en obligarse para obtener la prestación con que cuenta, vería burladas sus esperanzas si estuviese obligado a entregar lo que ha prometido sin recibir al mismo tiempo lo que se le prometió".

12 Cruz, María (2004) La exceptio non adimpleti contractus. Valencia: Editorial Tirant lo Blanch, p. 11. Planiol, Marcel y Ripert, Georges (1940) Tratado Práctico de Derecho Civil Francés, Las obligaciones. Tomo VI, traducción Mario Díaz Cruz, La Habana: Editorial Cultural, p. 612. "La parte sujeta a un contrato sinalagmático, frente a la negativa de la otra de cumplir su obligación ¿Qué conducta podrá adoptar? ¿Acudir a la vía judicial y al cumplimiento forzoso para obtener lo que se le debe o pedir la resolución? Le sería conveniente negarse a su vez al cumplimiento, provisionalmente, hasta el día en que la otra cumpla también, que es el derecho a no cumplir sino dando y dando o, conforme a la expresión usada por los juristas alemanes, trato por trato. En esto hallamos un medio de presión eficaz para provocar el cumplimiento correlativo sin exponer al que lo emplea a los riesgos del incumplimiento definitivo y a la insolvencia de su adversario, teniendo además la ventaja de no exigir la intervención de los Tribunales".

13 Traviesas, Miguel (1929) "Obligaciones Recíprocas". Revista de Derecho Privado, No 7, pp. 273-287, p. 331. 
una omisión total de la ejecución de la prestación por parte de quien reclama el cumplimiento de la contraprestación; y la excepción de contrato no cumplido adecuadamente, que es una variante o una modalidad de la excepción general de incumplimiento ${ }^{14}$. Esta última cabe en todos aquellos casos en que la prestación es cumplida de forma parcial o en forma defectuosa, es decir, cuando no se ha dado fiel obediencia a lo estipulado por las partes, existiendo un cumplimiento irregular o inoportuno. En efecto, cuando el demandante solo ha cumplido la prestación a su cargo parcialmente o de manera defectuosa, el demandado puede rehusar su propia prestación hasta que la primera haya sido cumplida totalmente o ejecutada de forma rigurosa, rectificando de modo pertinente los defectos que la prestación presentaba ${ }^{15}$.

Es importante, además, por el nivel de discusión que existe entre los diferentes autores nacionales, destacar brevemente el problema que suscita el ejercicio de la excepción de incumplimiento cuando se demanda la resolución. Para una parte de la doctrina ${ }^{16}$, el demandado puede oponer a dicha solicitud la exceptio non adimpleti contractus, cuando el acreedor no ha cumplido con su parte o no se encuentra llano a cumplirla, puesto que el cumplimiento de la obligación o estar llano a cumplirla es un requisito

14 Bozzo, Sebastián (2014) "La excepción de contrato no cumplido adecuada o regularmente y su régimen en el derecho civil español". Revista de Derecho de la Pontificia Universidad Católica de Valparaiso, No 42, pp. 83-119.

15 Dí́zz-Picazo (1996) 693. Este autor también agrega que la exceptio non rite adimpleti contractus contempla, además, aquellos casos en que se encuentra a cargo del demandante una garantía de correcto funcionamiento o de niveles de producción. Por ejemplo, el demandante ha vendido una máquina y ha asegurado su correcto funcionamiento y la posibilidad de alcanzar unos determinados niveles de rendimiento; De Cossio, Alfonso (1991) Instituciones de Derecho Civil, Parte General Obligaciones y Contratos. Madrid: Editorial Civitas, p. 336, indica lo siguiente: "La simultaneidad de las prestaciones que puede deducirse de las normas contenidas en los artículos 1.110 y 1.146 del Código Civil, si bien es evidente que la naturaleza específica de cada obligación puede llegar a modificar esta regla general. La parte que no ha cumplido su obligación no puede exigir a la otra el cumplimiento de la suya, ya que esta podrá siempre oponerle la exceptio non adimpleti contractus; posibilidad que se extiende incluso a los casos de cumplimiento defectuoso o irregular a través de la exceptio non rite adimpleti contractus, excepciones ambas que deberán, en su ejercicio, ser moderadas por el principio de la buena fe". En Chile se refiere a ella la Corte Suprema (14 de julio de 2008), rol 2830-2007; (27 de agosto de 2013), rol 7635-2012, y (18 de marzo de 2014), rol 951-2013, entre otras.

16 Ver Alessandri, Arturo (1931) "Nota a sentencia Corte Suprema, 29 de julio de 1931, 2a parte, secc. 1a". Revista de Derecho y Jurisprudencia, t. 8, p. 693; Rodríguez, Pablo (2003) "Acción resolutoria y excepción de contrato no cumplido". Revista Actualidad Jurídica, No 8, julio, Universidad del Desarrollo, pp. 69-83; Pizarro, Carlos (2005) "La excepción por incumplimiento contractual en el derecho civil chileno". En AA.VV., Estudios de Derecho Civil: Código y dogmática en el Sesquicentenario de la promulgación del Código Civil (Jornadas Nacionales de Derecho Civil, Valdivia, abril de 2005), Santiago de Chile: Editorial LexisNexis, pp. 324-333; Baraona, Jorge (1997) "La exigibilidad de las obligaciones". Revista Chilena de Derecho, vol. 24, No 3, pp. 503-523. 
exigido para ejercitar la resolución. Para otros ${ }^{17}$, en cambio, el artículo 1.489 C.C. no prevé condición de ningún tipo para exigir la resolución del contrato. En efecto, en materia de resolución, la excepción de incumplimiento solo tiene cabida para aquellos que entienden que para pedir la resolución se debe haber cumplido la prestación o estar llano a cumplirla. No así para los que entienden que no es un requisito y que es una facultad que se otorga por el artículo 1.489 C.C., siempre que el incumplimiento del deudor sea de carácter esencial.

\section{(1.1.1.) Presupuestos de la excepción de incumplimiento contractual}

La exceptio non adimpleti contractus exige determinados requisitos o presupuestos que se deben cumplir para que su ejercicio se ajuste a derecho y, por ende, cumpla con la función que se espera. La aplicación del instituto en estudio proviene principalmente de la deducción o interpretación del artículo 1.552 del Código Civil, pero también es posible considerar que se encuentra implícitamente contenida en todas las disposiciones que son manifestaciones del principio de simultaneidad en el cumplimiento de las obligaciones bilaterales ${ }^{18}$.

La excepción de incumplimiento contractual, así, tiene como fundamento o presupuesto, al igual que la figura de la compensación de la mora y de la resolución de los contratos por incumplimiento, (i) la existencia de una relación obligatoria sinalagmática ${ }^{19}$; (ii) obligaciones recíprocas, en el sentido de que los dos sujetos de la relación se encuentren obligados y que, por ende, ambos resulten también titulares de los correspondientes derechos de créditos; (iii) que dichas prestaciones sean exigibles, deban cumplirse de forma simultánea y que, a la vez, no se en-

17 Elgueta, Alejandra (1942) La resolución y el incumplimiento recíproco. Memoria de Licenciatura, Universidad de Chile, Santiago, pp. 121-122; Somarriva, Manuel (1939) Las obligaciones y los contratos ante la jurisprudencia. Santiago de Chile: Editorial Nascimento, p. 19; Peñailillo, Daniel (2003) Obligaciones. Teoría general y clasificaciones. La resolución por incumplimiento. Santiago de Chile: Editorial Jurídica, pp. 392-393; Aguad, Alejandra (2006) "Algunas reflexiones sobre los efectos del incumplimiento recíproco frente a la acción resolutoria". Revista Chilena de Derecho Privado, No 6, pp. 9-28, p. 28; AlCalde, Enrique (2003) "Acción resolutoria y excepción de contrato no cumplido". Actualidad Jurídica, No 8, pp. 68 y ss., p. 84; y VidaL, Álvaro (2008) "El incumplimiento resolutorio en el Código Civil, condiciones de procedencia de la resolución por incumplimiento". En AA.VV., Estudios de Derecho Civil IV, Jornadas Nacionales de Derecho Civil Olmué, Santiago de Chile: Editorial LegalPublishing, pp. 349-368.

18 Mejías Alonzo, Claudia (2013) 410.

19 Yúsari Khaliliyen, Tarek (2012) Incumplimiento Recíproco y Remedios Contractuales. Santiago de Chile, Thompson Reuters, p. 45 y sgtes. 
cuentren cumplidas por ninguna de las partes $^{20}$; (iv) y que finalmente, deban además ser ejercidas de buena fe.

\section{(1.2.) Contratos Vinculados}

\section{(1.2.1.) Noción de contratos vinculados}

El fenómeno de los contratos conexos está referido a la consecución de un determinado resultado económico, lo cual lleva a las partes a celebrar dos o más contratos diferentes que presentan entre sí un nexo jurídico, de tal forma que las vicisitudes que afectan a uno de ellos (vigencia, cumplimiento, incumplimiento, interpretación) repercuten en el otro y viceversa. De esta manera, estos contratos, a pesar de ser independientes, se hallan vinculados por voluntad de las partes, en virtud de la ley, o bien fruto del grado de identidad que media en la causa o el objeto de ambos ${ }^{21}$.

Siguiendo a López Frías, la conexidad contractual nace "cuando varios sujetos celebran dos o más contratos distintos que presentan una estrecha vinculación funcional entre sí por razón de su propia naturaleza o de la finalidad global que los informa, vinculación que es o puede ser jurídicamente relevante" 22 .

Por su parte, Larroumet ${ }^{23}$, al estudiar el efecto relativo de los contratos y el principio de inoponibilidad, examina casos que constituyen excepción a estos principios. Así, señala que la existencia de contratos coligados puede dar lugar a acciones extracontractuales directas de un tercero damnificado, como ocurre con el caso del consumidor que demanda contra el fabricante, o con el tercero dañado por hechos del subcontratista de obra que demanda al locatario principal de la obra. Avanza más en la cuestión cuando se ocupa de los grupos de contratos y de las acciones contractuales. En este sentido, dice el autor que el vínculo económico entre dos contratos se debe duplicar en uno jurídico y que, de una manera general, puede estimarse que siempre que el contrato entre A y B ha hecho necesaria la

20 En este sentido Mejías Alonzo, Claudia (2013) 407; Mejías Alonzo, Claudia (2014) "La excepción de contrato no cumplido, un análisis de su aplicación en la jurisprudencia nacional reciente y en la doctrina". Revista de Derecho Universidad Católica del Norte, Año $21 \mathrm{~N}^{\circ}$ 1, p. 113 y sgtes.; Caprile, Bruno (2012) 53.

21 Bernad Mainar, Rafael (2010) A propósito de una pretendida teoría general de los contratos conexos. Revista Crítica de Derecho Inmobiliario, No 720, pp. 1447-1484, p. 1451.

22 López Frí́as (1994) 34.

23 Larroumet, Christian (1998) Responsabilidad civil contractual. Algunos temas modernos. Santiago de Chile: Editorial Jurídica de Chile, p. 193. 
celebración de un contrato entre $\mathrm{B}$ y $\mathrm{C}$, el perjuicio sufrido por $\mathrm{B}$ como consecuencia de un incumplimiento de la obligación contraída por A hacia $\mathrm{B}$ deberá ser reparado. De este modo, $\mathrm{B}$ tiene una acción contra $\mathrm{C}$ y contra $\mathrm{A}$. La tesis más avanzada en este sentido sostiene que quien integra un grupo de contratos no es un tercero y, por ello, puede tener una acción contractual. Llegado a este punto, el autor se detiene a señalar las dificultades que presenta una interpretación laxa del principio de la relatividad de los contratos y de su inoponibilidad. En tal sentido, asevera que es difícil establecer límites y que no hay una definición del grupo de contratos.

Ahora bien, siguiendo lo expuesto, los contratos vinculados en materia de consumo se caracterizan por la relación entre el contrato de adquisición del servicio o del bien y el contrato de financiación. Esto significa la existencia de una cierta colaboración entre la entidad financiera y la entidad suministradora del bien o servicio. En esta situación, aunque existan dos contratos documentalmente, no existe una relación independiente entre el consumidor y la entidad financiera, sino que al iniciarse la relación del consumidor con la empresa suministradora del bien o del servicio, ya se prevé la colaboración de una entidad financiera con esta última ${ }^{24}$.

\section{(1.2.2.) Presupuestos de los contratos vinculados}

Para comprender mejor acerca de los requisitos que debiesen concurrir para la configuración de la vinculación contractual, analizaremos cómo han articulado esta vinculación contractual otros sistemas jurídicos y en especial la última Directiva de la Unión Europea que sirve de base a los ordenamientos de cada uno de los países que la integran.

A. Presupuestos bajo la Directiva 2008/48/CE 25

Según el artículo 3.n) de la nueva Directiva, para que exista un contrato de crédito vinculado deben concurrir los siguientes requisitos:

i. que el contrato de crédito sirva exclusivamente para financiar un contrato relativo al suministro de bienes específicos o a la prestación de servicios específicos;

24 Bozzo, Sebastián (2015) 41.

25 La Directiva 2008/48/CE, del Parlamento Europeo y del Consejo, de 23 de abril de 2008, relativa a los contratos de crédito al consumo, deroga la Directiva 87/102/CEE. Esta nueva Directiva consta de 32 artículos y tres anexos. El texto introdujo importantes modificaciones al régimen del crédito al consumo en los diferentes países miembros, obligándoles a adoptar cambios en su legislación interna. El principal propósito de la Directiva era conseguir una armonización total para garantizar que todos los consumidores de la Unión Europea puedan beneficiarse de un nivel elevado y equivalente de protección de sus intereses y para crear un autentico mercado interior. 
ii. que los dos contratos constituyan una unidad comercial desde un punto de vista objetivo.

De esta forma, el legislador europeo abandona, con acierto, el requisito del "acuerdo previo en exclusiva" recogido en la antigua Directiva $87 / 102 / C E E$.

Se puede destacar, además, que de esta Directiva se extraen, en cuanto a los contratos vinculados dos importantes consecuencias. La primera tiene relación con la posibilidad de que si el consumidor desiste del contrato de consumo, dejará de estar obligado por el contrato de crédito vinculado (art. 15.1 DCCC). La segunda, en el caso que el proveedor del bien o servicio incumple, tendrá "derecho de recurso" (art. 15.2 DCCC). La norma comunitaria no concreta qué derechos en particular puede ejercitar el consumidor contra el prestamista, cuestión que es entregada para su regulación a los Estados miembros, para que en sus respectivas leyes nacionales de incorporación dispongan lo que estimen necesario.

B. Presupuestos bajo la Ley $16 / 2011$ de Crédito al Consumo española ${ }^{26}$. La ley española ha traspuesto de forma exacta el artículo 3.n) de la Directiva, señalando en su artículo 29.1 LCCC:

i. que el crédito contratado sirve exclusivamente para financiar un contrato relativo al suministro de bienes específicos o a la prestación de servicios específicos;

ii. que los dos contratos constituyan una unidad comercial desde un punto de vista objetivo.

En definitiva, los requisitos para que dos contratos puedan considerarse vinculados en materia de consumo deben ser especialmente dos: primero, la pluralidad contractual, es decir, efectivamente se deben celebrar dos contratos, ya que es evidente que es necesario que existan dos contratos, de lo contrario, no se puede hablar de vinculación, y segundo, debe existir una conexión funcional entre los contratos de crédito y consumo.

Por otra parte, no es requisito esencial para la existencia de contratos vinculados que el contrato sea celebrado con dos personas diferentes, pudiendo los dos contratos ser concertados con el mismo sujeto pero en representación de una o más personas diversas. Tampoco es nece-

26 Esta Ley deroga la vieja Ley 7/1995, de 23 de marzo, de crédito al consumo. La finalidad de la misma era entre otras la de incorporar la Directiva europea, pero además se incluyeron otras materias que no tenía como propósito armonizar la normativa interna en España. 
sario que el consumidor desconozca que contrata con dos individuos distintos. Esto es así, porque la necesidad de protección al consumidor -como ya hemos indicado- no proviene de que el consumidor crea que contrata con una sola persona, sino de los perjuicios jurídicos que le ocasiona el desdoblamiento de una única operación económica en dos contratos ${ }^{27}$.

Para que la conexión funcional opere es necesario que los dos contratos estén funcionalmente unidos, es decir, enlazados. Sin embargo, la dificultad se presenta en poder establecer esta conexión funcional. Como señala Marín López ${ }^{28}$, el criterio determinante de la conexión funcional se encuentra en la doctrina de la causa, especialmente en la llamada "causa final", entendiendo por esta el propósito empírico o práctico que las partes tratan de conseguir mediante la celebración del contrato ${ }^{29}$. Así, la finalidad concreta perseguida por los contratantes deja de ser un motivo interno, personal, para trascender al contrato y adquirir relevancia jurídica. En consecuencia, existirá un nexo funcional entre los dos contratos cuando a través de ellos las partes pretenden alcanzar un resultado económico que está relacionado entre sí y que de no estarlo, estaría en duda su celebración ${ }^{30}$.

\section{Situación en Chile}

En Chile -como indicábamos- no existe una regulación legal que aborde el problema de los contratos vinculados en materia de consumo. Por su parte, la doctrina solo se ha aproximado de forma general a la teoría de contratos conexos. Así, el profesor López Santa María ${ }^{31}$, quien ha desarrollado de manera extensa el problema de los contra-

Marín López, Juan Manuel (2014) Comentarios a la Ley de Contratos de Crédito al Consumo. Pamplona: Aranzadi, p. 1043.

29 Vial del Río, Víctor (2003) Teoría General del Acto Jurídico. Santiago de Chile, Editorial Jurídica de Chile, p. 190. Rivera Restrepo, José (2011) "Una mirada a la doctrina de la causa y sus distintas versiones en el código civil chileno". Revista de Derecho de la Universidad Católica del Norte, Año 18, No 2, pp. 310.

Para profundizar sobre la materia revisar Bozzo, Sebastián (2015) 39-66.

López Santa María, Jorge (1998) "Las cadenas de contratos o contratos coligados". Revista de Derecho de la Universidad Católica de Valparaíso, No 19, pp. 159-166, p. 160; Pizarro Wilson, Carlos (2005) "La interdependencia de contratos que forman un mismo grupo contractual en el derecho francés". Revista Estudios Socio-jurídicos, No 7, pp. 66-74, p. 67, indica sobre este tipo de contratos lo siguiente: "El principio de que los contratos producen efectos nada más entre las partes pareciera ser desmentido por los denominados grupos de contratos o contratos conexos. Se trata de dos o más contratos cuyo objetivo económico es común y, por ende, se encuentran vinculados. Esta figura permitiría, en ciertas condiciones, que la nulidad o resolución de uno de los contratos del conjunto signifique la ineficacia de los otros actos jurídicos que participan del mismo. Los efectos de un contrato tendrían, entonces, una resonancia significativa en la eficacia de otros actos jurídicos con los cuales se encuentra vinculados por una interdependencia de naturaleza económica. Un acto jurídico se vería afectado y, en consecuencia las partes que participan en el mismo, por la ineficacia 
tos relacionados, sí ha identificado que los créditos al consumo dan nacimiento a contratos conexos. De esta forma, indica que "[h]ay no pocas modalidades de créditos al consumo, una de las cuales son los contratos con utilización de tarjeta de crédito: al contrato entre la entidad que emite la tarjeta y el establecimiento comercial, se une el contrato entre esa misma entidad y el consumidor, y luego la compraventa entre el comerciante y el consumidor".

\section{2) EJERCICIO DE LA EXCEPTIO EN PROCEDIMIENTOS DE EJECUCIÓN}

Para analizar el ejercicio de la exceptio en el juicio ejecutivo cabe estudiar dos problemas: el primero es determinar si es admisible discutir en un juicio de ejecución cuestiones que dicen relación con el cumplimiento o incumplimiento de un contrato, que por su naturaleza son de lato conocimiento. El segundo problema dice relación con establecer si es posible ejercitar la excepción de incumplimiento en un juicio de ejecución en contra del financista cuando quien ha incumplido es el vendedor del contrato de compraventa.

\section{(2.1.) OPOSICIÓN DE LA EXCEPTIO EN EL JUICIO EJECUTIVO}

El juicio ejecutivo se concibe en nuestro ordenamiento como un procedimiento contencioso que puede ser de aplicación general o especial y de tramitación extraordinaria, con el propósito de perseguir el cumplimiento forzado de una obligación que consta de un título fehaciente e indubitado, es decir, que tiene como fundamento una obligación cuya existencia se halla establecida de manera cierta, ya que de lo contrario sería necesario seguir la vía del procedimiento declarativo u ordinario ${ }^{32}$.

sufrida en otro contrato. En este sentido el principio del efecto relativo de los contratos se vería lesionado".

32 Casarino, Manuel (2009) Manual de Derecho Procesal Civil. Tomo V, Santiago de Chile: Editorial Jurídica de Chile, p. 43; Espinosa, Raúl (2003) Manual de Procedimiento civil, El juicio ejecutivo. Santiago de Chile: Editorial Jurídica de Chile, p. 7, señala que el juicio ejecutivo puede definirse como un procedimiento contencioso especial que tiene por objeto obtener, por vía de apremio, el cumplimiento de una obligación convenida o declarada fehacientemente, que el deudor no cumplió en su oportunidad; Quezada, José (2012) Proceso ejecutivo. Santiago de Chile: Editorial Librotecnia, p. 35, puntualiza sobre el título ejecutivo: "El título debe bastarse a sí mismo y contener todos los elementos necesarios para el ejercicio de la acción ejecutiva; por esto, considero que es un documento solemne al cual la ley acuerda acción ejecutiva. La expresión documento está tomada en su sentido restrictivo de instrumento, o sea, de documento que expresa un pensamiento por medio de la escritura. Sus elementos son:

$\left.1^{\circ}\right)$ Es un documento, en el sentido de instrumento. 
Junto con el título ejecutivo se exige para iniciar la acción ejecutiva que la obligación sea actualmente exigible, esto es, líquida o determinada y que la acción no se encuentre prescrita.

El requisito de la exigibilidad es el que merece nuestra atención y estudio, entendiéndose que es actualmente exigible cuando es ejecutable pura y simplemente, es decir, no se halla sujeta a ninguna modalidad, sea condición, modo o plazo. El momento en que debe concurrir la exigibilidad de la obligación es aquel en que se ejercita la acción ejecutiva mediante la presentación de la demanda ejecutiva.

Respecto de los contratos bilaterales de cumplimiento simultáneo es necesario despejar la duda si para iniciar este procedimiento es irrelevante o no que el acreedor haya cumplido con su obligación, o si bien es suficiente el solo incumplimiento del deudor.

El artículo 1.552 del C.C. chileno expresa que en los contratos bilaterales ninguno de los contratantes está en mora dejando de cumplir lo pactado, mientras el otro no lo cumple por su parte o no se allana a cumplirlo en la forma y tiempo debidos. Por lo tanto, cabe preguntarse si el ejecutado puede oponer la excepción de contrato no cumplido cuando la obligación emana de un contrato bilateral de cumplimiento simultáneo. Es decir, ¿ ¿debe el acreedor ejecutante haber cumplido con su obligación o, por lo menos, que está llano a cumplirlas en la forma y tiempo debidos?

El Código de Procedimiento Civil chileno no explica qué se debe entender por "obligación actualmente exigible", término que la doctrina y jurisprudencia han precisar ${ }^{33}$. Si bien -como se ha indicado- la exigibilidad se asocia a que la obligación no se encuentre sujeta a modalidad alguna, no se puede obviar que en el ámbito de la ejecución de los contratos bilaterales, la falta de cumplimiento del acreedor puede volverse en su contra, ya que el ejecutado puede reclamar mediante el artículo 464

$\left.2^{\circ}\right)$ Debe ser solemne: exigencia que se advierte en dos presupuestos: a) debe ser escrito, y b) debe cumplir con las solemnidades legales, especialmente impuestos (letras de cambio), o autorización (sentencia).

$3^{\circ}$ ) El título debe contener el reconocimiento o declaración de un derecho y su correlativa obligación, que puede ser de dar, hacer o no hacer".

33 BaraOna (1997) 521, señala al respecto que “... la simultaneidad en el cumplimiento se convierte en requisito de exigibilidad para las obligaciones bilaterales, de tal manera que solo puede hacerse exigible la obligación correlativa, cumpliendo o manifestando disposición al cumplimiento quien pretende exigir su pago. Si inexigible, quiere decir que tampoco hay retraso -entendiendo por ello la falta de cumplimiento oportuno de la obligación- pues no nace el deber actual de cumplir, sino con el cumplimiento o allanamiento de la contraria. Así, ambas obligaciones quedan en estado inexigible hasta que una de las partes se decida a cumplir, para lo cual bastará con hacerlo o que se solicite el cumplimiento a su contraparte, dándole cuenta de su disposición al cumplimiento simultáneo”. 
No 7 del Código de Procedimiento Civil la falta de exigibilidad, fundado en el artículo 1.552 del C.C. El artículo 464 No 7 del C.P.C. faculta al ejecutado oponerse a la demanda cuando falte alguno de los requisitos o condiciones establecidos por las leyes para que dicho título tenga fuerza ejecutiva, sea absolutamente, sea en relación con el demandado ${ }^{34}$.

De esta forma, el título ejecutivo no tendría fuerza ejecutiva si lo que se pretende hacer cumplir es un contrato bilateral de cumplimiento simultáneo y el ejecutante no ha cumplido con su prestación ${ }^{35}$. El contrato bilateral genera obligaciones para todos los contratantes, y no es exigible la obligación de que da cuenta el contrato y que pesa sobre una de las partes mientras la otra no cumpla o se allana a cumplir sus obligaciones correlativas. En consecuencia, conforme al artículo 1.552 del C.C., para que la obligación que emana de un contrato sea exigible, es menester que se cumpla por el otro u otros contratantes las obligaciones que pesan sobre ellos, o que están llanos a cumplirlas ${ }^{36}$.

La exceptio admite, pues, la paralización o suspensión del contrato, en cuanto permite a quien la opone no cumplir mientras la contraparte no lo haga. Dicha suspensión o paralización del cumplimiento no viene por el hecho de que se haya opuesto la exceptio, sino que ella se puede oponer porque la obligación es inexigible: es decir, la inexigibilidad es causa y no efecto de la excepción de contrato no cumplido ${ }^{37}$.

34 Gruss, Guillermo (1998) Juicio Ejecutivo. Tomo I, Santiago de Chile: Editorial Jurídica la Ley, p. 149; Quezada (2012) 165.

35 La Corte de Apelaciones de Santiago, en sentencia de fecha 17 de agosto de 1992, acogiendo un recurso de apelación, revocó la sentencia apelada y dio lugar a la excepción del No 7 del art. 464 del C.P.C., al entender que no podía pedirse la ejecución de una obligación si el ejecutante por su parte no había cumplido correctamente su obligación, pues faltaba un elemento esencial para la ejecución: cual es su exigibilidad. El caso en cuestión trataba de la exceptio non rite adimpleti contractus. Sobre el particular, véase CoRTe de Apelaciones DE Santiago de Chile. 17 de agosto de 1992. Sin rol. En Revista de Derecho y Jurisprudencia, T. LXXXIX, Nº 2, segunda parte, sección segunda, pp. 124-125.

36 Ramírez, Fernando (1962) La excepción de contrato no cumplido en el juicio ejecutivo. Memoria de Prueba para optar al Grado de Licenciado en Ciencias Jurídicas y Sociales de la Universidad de Chile, Santiago de Chile: Editorial Universitaria, p. 35.

37 Abeliuk (1993) 779; Fueyo, Fernando (1992) Cumplimiento e Incumplimiento de las obligaciones. Santiago de Chile: Editorial Jurídica de Chile, p. 429, entiende que la exceptio lo que permite o legitima es a no cumplir si la contraparte a su vez no cumple; la idea es lógica, pero creo que explica mejor esta situación la figura de la inexigibilidad, pues la conducta del excipens no solo es legítima, sino que no puede calificarse ni siquiera como no cumplimiento, pues no hay deber actualizado de cumplir. 


\section{(2.2.) EJERCICIO DE LA EXCEPTIO EN UN PROCEDIMIENTO DE EJECUCIÓN ANTE EL INCUMPLIMIENTO DE CONTRATOS VINCULADOS}

Si se produce el incumplimiento del vendedor del contrato de compraventa que se encuentra vinculado al contrato de crédito, nada impediría actualmente que el acreedor del crédito que financió la adquisición del bien o servicio exija por su parte las cuotas del prestamo, mediante un juicio ejecutivo de cumplimiento del contrato. Este procedimiento debiese ser lo habitual, puesto que lo normal es que la deuda se haya documentado con un pagaré o letra de cambio, quedando el acreedor con un título ejecutivo para iniciar directamente el procedimiento de cobro.

En el caso de que se cumplan los supuestos de la contratación vinculada, ¿es posible que el consumidor se oponga en el juicio ejecutivo por medio de la excepción de incumplimiento contractual? La pregunta cabe formularla, dado que no se ha incumplido el contrato de crédito, sino que se ha quebrantado el contrato de compraventa en el cual no ha participado el financista. Este es un tercero respecto del contrato de compraventa y conforme a los principios generales de la contratación, en especial el principio del efecto relativo de los contratos, no podría ser alcanzado por los efectos de un contrato en el cual no ha participado manifestando su voluntad.

Ahora bien, creemos que el principio del efecto relativo de los contratos $\mathrm{u}$ otro motivo que se alegue no es un real impedimento para oponer la exceptio non adimpleti contractus en caso de incumplimiento o la exceptio non rite adimpleti contractus en el caso de que el contrato de compraventa se haya cumplido de manera defectuosa. Esto, por los siguientes motivos:

i. En nuestro ordenamiento no existe una consagración legal de este principio $^{38}$, pero se arriba a este gracias al artículo 1.545 del Código Civil, el cual establece que el contrato válidamente celebrado es una ley para las partes ${ }^{39}$. Si bien en Chile el efecto relativo de los contratos tiene un amplio reconocimiento doctri-

\footnotetext{
38 En cambio, en Francia, el nuevo código del 1 de octubre del 2016 en su artículo 1.199, señala que el contrato crea solo obligaciones entre las partes. En España por su parte el artículo 1.257 del Código del ramo, indica que "los contratos solo producen efectos entre las partes que lo otorgan y sus herederos".

39 Henríquez Herrera, Ian (2012) "Para una delimitación del efecto expansivo de los contratos. Comentario a la sentencia de la Corte Suprema de 25 de enero de 2011 Casación en el fondo Rol No 3738-2009”. Revista Chilena de Derecho, vol. 39, No 2, pp. 513-522, p. 514.
} 
nal, este principio presenta matices, al igual que en aquellos ordenamientos en los cuales el principio tiene un reconocimiento expreso $^{40}$.

ii. La doctrina nacional mediante uno de sus mayores exponentes, el profesor López Santa María ${ }^{41}$, al referirse a las excepciones al principio del efecto relativo de los contratos, señala que es posible concluir que un contrato es capaz de crear derechos o imponer una obligación a un penitus extranei sin su consentimiento. El efecto expansivo o efecto absoluto de los contratos no hace nacer un derecho u obligación directamente para el tercero, sino que este más bien puede invocar un contrato ajeno, ya que ese contrato indirectamente lo afecta en su situación jurídica y patrimonial. El efecto expansivo del contrato se sitúa en una perspectiva más amplia que la del principio tradicional del efecto relativo, superando la rigidez y estrechez del efecto relativo, esto es una suerte de abandono o sustitución de los marcos que encuadran la institución del efecto relativo, para situar el análisis jurídico a otra altura, menos dogmática y más realista ${ }^{42}$.

iii. También cabe la posibilidad de considerar parte del contrato a quien no ha concurrido con su voluntad a celebrarlo, esto por la naturaleza jurídica de los contratos vinculados, ya que debido al nexo contractual que deriva de la conexión causal de los negocios

Dítz-Picazo (1996) 425, señala al respecto: "Debemos convenir desde ahora en que el contrato como fenómeno que penetra y que se instala en la realidad jurídica no es jamás algo absolutamente indiferente para los terceros. Existe en nuestro CC toda una serie de preceptos que van despojando a la regla del art. 1257 -los contratos solo producen efecto entre las partes - de una gran parte de la fuerza que a primera vista parecía tener. Un examen atento de diversos pasajes puede desplegar una cierta eficacia respecto de terceros".

41 López Santa María, Jorge (2005) Los contratos. Tomo II, Santiago de Chile: Editorial Jurídica de Chile, p. 308. El profesor Domínguez Águila, Ramón (1983) "Los terceros y el contrato". Revista de Derecho de la Universidad de Concepción, No 51, p. 153, ha dicho, en el mismo sentido, que no es efectivo que el contrato sea inoponible a terceros. Muy por el contrario, el contrato es, por esencia, oponible a todos, porque nadie puede desconocer el contrato convenido entre otros, ni puede, por lo mismo, impedir, ni privar, ni discutir a las partes los derechos y obligaciones que provienen del contrato. Señalando que el contrato no es únicamente una cuestión de creación de norma legal y de imperio de voluntad. Se inscribe en un contexto social y, por lo mismo, es también un hecho social. Por lo tanto, sostiene que afirmar que los contratos son inoponibles a terceros es inexacto, que no ayuda a entender el problema. Hay todo un radio de repercusión del contrato que va desde las partes hasta terceros más próximos y otros cada vez más lejanos.

42 Vidal Olivares, Allvaro (2006) "El efecto absoluto de los contratos". Revista Chilena de Derecho Privado, No 6, pp. 51-86, señala que en diversas ocasiones, al margen de la voluntad de las partes contratantes, un contrato puede ser invocado por un tercero en su favor u opuesto a un tercero en su detrimento. Teniendo presente que un contrato en ciertas circunstancias puede ser un hecho que como tal existe para todos, en sus efectos reflejos puede alcanzar a terceros absolutos: no para crear directamente un derecho o una obligación en el patrimonio de ellos, sino en cuanto es factible traerlo a colación o formular una pretensión basada en el contrato ajeno. 
conexos hace que cada uno de sus miembros, por su convergencia hacia una finalidad común, no sean extraños entre sí y que, por ende, los sujetos contratantes que intervienen en el grupo contractual no sean verdaderos terceros. Es decir, los miembros que concurren a la celebración de cada uno de los contratos individuales pueden ser asimilados al concepto de partes, por lo que el principio de los efectos relativos de los contratos se podría aplicar sin excepción ${ }^{43}$.

iv. Es posible además sostener, bajo la teoría de la conexión causal de los contratos vinculados, que las incidencias producidas en el contrato de compraventa deben provocar algún tipo de consecuencia jurídica en el contrato crediticio, y esto se produce gracias a la conexión causal existente entre los negocios jurídicos. La vinculación causal entre los dos contratos tiene lugar cuando la concesión crediticia es resultado de la colaboración planificada entre prestamista y vendedor ${ }^{44}$. En este sentido, si el contrato de prestamo tenía como causa directa el contrato de compraventa, y al caer este como ineficaz, se debe entender que el contrato de prestamo queda carente de causa y, por lo tanto, de un elemento esencial de él para seguir produciendo sus efectos. Indudablemente, cuando el acto nace a la vida del derecho reunía todos los elementos esenciales exigidos, por lo que el contrato no es nulo, sino que deviene en ineficaz y deben las partes volver al estado en que se encontraban antes de contratar, puesto que los motivos particulares que las partes tuvieron en cuenta al momento de

43 Pizarro Wilson, Carlos (2007) "El Efecto relativo de los contratos: partes y terceros". En El Código Civil de Chile (1855-2005), Editor: Alejandro Guzmán Brito, Santiago de Chile: LexisNexis, p. 567, quien señala: "Las precedentes explicaciones han tenido por objeto revisar el efecto relativo de los contratos desde una perspectiva algo diferente. No se trata de anclar toda la teoría contractual en el dogma de la autonomía de la voluntad. La controversia sobre este asunto debe tenerse por superada, siendo posible un análisis distinto del efecto relativo de los contratos que permita extender la noción de partes en presencia de cadenas de contratos".

44 Marín López, Juan Manuel (2003) "Dictamen jurídico sobre el caso English Opening School: crédito al consumo, cesión de créditos y contratos vinculados". Revista Crítica de Derecho Inmobiliario, vol. 79, No 677, pp. 1735-1794; al referirse a la vinculación contractual señala: "Con carácter general, cabe sostener que el criterio determinante de la conexión funcional hay que buscarlo en la doctrina de la causa. Los dos contratos estarán vinculados cuando a través de ellos las partes pretendan alcanzar un único resultado económico. En el ámbito del crédito al consumo, habrá vinculación contractual cuando los dos contratos se han celebrado con el fin de facilitar al consumidor la adquisición de bienes de consumo con pago a plazos; esto es, cuando los dos contratos puedan considerarse, en función de datos objetivos, como partes de una única operación económica, debido a que prestamista y vendedor colaboran para permitir al consumidor la adquisición de bienes a plazos". 
cerrar el negocio desaparecen, dejando al acto desprovisto de una causa que justifique mantenerlo.

Dado que las consecuencias del incumplimiento del vendedor no son menores, pues según la teoría general de los contratos el consumidor deberá seguir cumpliendo con las cuotas del crédito pactadas, es necesario morigerar el principio del efecto relativo de los contratos y defender, por otra parte, la teoría de la conexión causal que presentan los contratos vinculados. Esto conlleva así analizar desde una perspectiva unitaria las relaciones de consumo, ya que si bien existen diversos contratos, se genera una vinculación entre el grupo contractual por la interacción de fines entre las distintas relaciones jurídicas.

\section{3) EL EJERCICIO DE LA EXCEPTIO RESPECTO DE OTROS JUICIOS DE EJECUCIÓN}

\section{(3.1.) Cobro EJECUTIVO DE LETRAS, PAGARÉS Y CHEQUES}

El denominador común de la letra, pagaré y cheque es que son títulos de créditos, los cuales gozan de una autonomía que permite al adquirente de un título obtener la titularidad de este en forma originaria, es decir, su derecho no deriva del tradente, sino que nace nuevo en el que adquiere al recibir el documento.

En este sentido, el acto cambiario es independiente y abstracto. Independiente porque así se desprende del artículo $7^{\circ}$ de la Ley No 18.092, al expresar que para la validez de los distintos actos cambiarios es suficiente la firma del obligado. Además es abstracto o no causado, dado que el que lo ha suscrito, ya sea como girador, aceptante o endosante, está obligado al pago a su tenedor legítimo con entera independencia de la existencia y validez de la obligación subyacente o negocio causal que ha servido de base a su creación. Es por esto que en el título no hay referencia alguna a la relación jurídica ${ }^{45}$.

45 Vergara Bezanilla, José Pablo (2013) "La inoponibilidad de las excepciones en la cesión de créditos expresados en facturas". Revista de Derecho, No 30, p. 38; VArgas Vargas, Manuel (1998) Nueva Ley sobre Letras de Cambio y Pagarés. Santiago de Chile: Editorial Jurídica de Chile, p. 55; Ubilla Grandi, Luis Eugenio (1995) Teoría General de la Letra de Cambio y Pagaré en la ley 18.092. Santiago: Editorial Jurídica de Chile, pp.71 y 72. 
Lo anterior lo reafirma el profesor Álvaro Puelma ${ }^{46}$ al señalar: "En razón de que los actos cambiarios son unilaterales, independientes y abstractos, se deduce doctrinariamente que ellos son jurídicamente independientes del negocio causal que le dio origen, principio que se justifica por las necesidades de circulación y pago del documento, pues obstan a ellos que la validez y el cumplimiento de los actos cambiarios se subordinen o dependan del cumplimiento o validez del negocio causal que le dio origen".

De todo lo anterior es posible arribar al principio cambiario de inoponibilidad de excepciones que el legislador estableció en el artículo 28 de la Ley $\mathrm{N}^{\circ} 18.092$ en los siguientes términos: "La persona demandada en virtud de una letra de cambio no puede oponer al demandante excepciones fundadas en relaciones personales con anteriores portadores de la letra".

De esta forma, la letra de cambio, pagaré y cheque constituyen documentos abstractos e independientes solo respecto de los terceros o personas ajenas a la relación fundamental o negocio que le dio origen, con lo cual se garantiza su expedita circulación y la seguridad de su tráfico jurídico, sin consideración de la parte que lo suscribe. Ahora bien, entre las partes que celebraron el negocio jurídico que generó el acto cambiario, este no reviste el carácter de abstracto o independiente, por cuanto entre ellos dicho acto resulta directamente relacionado o vinculado al negocio causal. De este modo, en caso de un hipotético juicio ejecutivo, el demandado puede oponer las excepciones reales que consten del instrumento y las personales suyas que pueda hacer valer en contra del acreedor ${ }^{47}$.

A la luz de lo anterior solo se podría oponer la excepción del contrato no cumplido en contra del tenedor del título de crédito cuando este no haya circulado. En caso de circulación del título, su tenedor podría, en razón del artículo 28 de la Ley $\mathrm{N}^{\circ} 18.092$ hacer valer el principio cambiario de inoponibilidad de excepciones.

Si la venta del bien o servicio ha sido financiada por el vendedor mediante letras, pagarés o cheques, las posibilidades del consumidor de ejercitar la excepción del contrato no cumplido son bajas, puesto que bastaría que la contraparte del contrato que ha incumplido ceda el crédito a un

\footnotetext{
46 Puelma Accorsi, Álvaro (1999) Letra de cambio y pagaré Ley No 18.092. Santiago de Chile: Editorial Jurídica de Chile, p. 21.

47 En este sentido, Corte de Apelaciones de Santiago de Chile. 11 de noviembre de 2013. Rol No 7152-2012. Disponible en: basejurisprudencial.poderjudicial.cl [fecha de visita: 1 de septiembre de 2016].
} 
tercero, para que este lo cobre independientemente del cumplimiento del vendedor del bien o servicio adquirido por el consumidor.

Por otro lado, si la venta ha sido financiada por un tercero, cabe preguntarse si es posible aplicar la teoría de los contratos vinculados en caso de incumplimiento del vendedor, para evitar así que el consumidor pague las cuotas del crédito pendientes. En este caso, el prestamista pudo haber exigido al consumidor letras u otro título para lograr así un cobro expedito del crédito. Pues bien, en el evento de que el título respectivo no haya aún circulado, si aplicamos la teoría de los contratos vinculados, podría considerarse parte del contrato de compraventa del bien o servicio a quien otorgó el crédito y posee a su vez el título. Esto último, siempre que se cumplan los presupuestos de la contratación vinculada que haga verosímil la aplicación de la referida teoría. En dicho evento podría el consumidor defenderse oponiendo la excepción del contrato no cumplido en contra del prestamista.

El gran problema que enfrenta el consumidor en las adquisiciones financiadas por medio de instrumentos como pagarés y cheques es que siempre es posible ceder dichos títulos a un tercero, lo que impediría -según lo visto- el ejercicio de la excepción de contrato no cumplido. Además, esta cesión puede llegar a ser fraudulenta, en el caso de que se obre a sabiendas en perjuicio del deudor.

Es importante precisar que, por ejemplo, en España la Ley Cambiaria y del Cheque 19/1985 del 16 de julio otorga en su artículo 67, párrafo primero, la posibilidad del deudor cambiario de oponer las excepciones basadas en sus relaciones personales con el tenedor. Además, permite formular aquellas excepciones personales que él tenga frente a los tenedores anteriores si al adquirir la letra el tenedor procedió a sabiendas en perjuicio del deudor ${ }^{48}$.

Además en materia de contratos de crédito al consumo la Ley 16/2011 de 24 de junio, en el artículo 31 dispone que en caso de cesión de un crédito al consumo a un tercero, el consumidor podrá oponer a este tercero las mismas excepciones y defensas que hubiera podido oponer contra el acreedor originario, incluida la compensación. Esta norma es de carácter inderogable, considerándose nula cualquier cláusula que pretenda que el consumidor renuncie total o parcialmente a ejercitar sus derechos contra el cesionario en caso de cesión de créditos.

48 Véase Esteban, Ignacio (2012) "Alcance de la excepción de incumplimiento del negocio causal en el juicio cambiario". Actualidad Civil, No 3, pp. 269-279, p. 272; Peiteado, Manuel (2004) "La exceptio non rite adimpleti contractus en la oposición al juicio cambiario". Revista de Derecho Bancario y Bursátil, No 95, año 23, p. 238. 
Estas normas serían de gran ayuda para el consumidor si se incluyera en nuestra legislación, ya que no bastaría la cesión del crédito para que el vendedor o prestamista se eximan de su responsabilidad.

\section{(3.2.) Cobro EJECUTIVo de FaCturas}

La Ley No 19.983 confirió mérito ejecutivo a la cuarta copia de la factura, cumpliendo dos propósitos: el primero, ser un documento de naturaleza tributaria y, segundo, tener hoy un carácter de "título de crédito".

La factura es un "título de valor", de la especie de los representativos de dinero. En ella consta el estado de pago del precio o remuneración $y$, en su caso, de las modalidades de solución del saldo insoluto, lo que implica la conexión permanente al documento de una declaración de contenido obligacional, respecto del deudor, y de un crédito, respecto del acreedor, con las características de irrevocable e incondicionado, tal como ocurre en los demás títulos representativos de dinero. Además, este crédito incorporado a la factura es negociable, toda vez que ella es transferible o cesible y esta cesibilidad ha de aparecer en su tenor ${ }^{49}$.

Aun cuando la factura, al igual que la letra, pagaré y cheque, es un título de valor, se diferencia al ser un título causado y no abstracto, pues la exigencia impuesta por la ley para que tenga mérito ejecutivo y sea transferible obliga a que en la copia de la factura conste el recibo de la mercadería o de la prestación de servicio; por ende, esto da testimonio de que la factura tiene su origen en una relación subyacente que constituye su causa. De esta forma se prohíbe que la factura pueda emitirse al portador o con cláusula a la orden, por tratarse justamente de un título de valor causado ${ }^{50}$.

Para que la factura tenga mérito ejecutivo para su cobro, deben cumplirse ciertos requisitos, los cuales se establecen en el artículo $5^{\circ}$ de la Ley $\mathrm{N}^{\circ} 19.983$ y son los siguientes:

i. Que la factura correspondiente no haya sido reclamada de conformidad al artículo $3^{\circ}$ de esta ley. Es decir, no se debe haber devuelto la factura y la guía o guías de despacho, en su caso, al momento de la entrega, o no se haya reclamado en contra de su ca de Chile, p. 103.

50 Prado Puga, Arturo (2016) "Alcance jurídico de la factura como título de circulación mercantil". Revista de Derecho de la Pontificia Universidad Católica de Valparaíso, No 46, p. 170. 
contenido dentro de los ocho días corridos siguientes a su recepción, o en el plazo que las partes hayan acordado, el cual no puede exceder de treinta días corridos.

ii. Que su pago sea actualmente exigible y la acción para su cobro no esté prescrita.

iii. Que conste en la factura el recibo de las mercaderías o de la prestación del servicio, e identificación de la persona que recibe las mercaderías o el servicio y la firma de este último.

Además, conforme al artículo 4o letra a) de la misma ley, la factura debe ser emitida en concordancia con las normas que rigen la emisión de la factura original, es decir, se debe indicar el nombre y domicilio de las partes, el Rol Único Tributario de cada una de ellas, el detalle de la mercadería transferida o la naturaleza del servicio prestado, el precio unitario y el monto de la operación ${ }^{51}$.

Cumplidos estos requisitos, la factura tendrá mérito ejecutivo una vez que el título sea puesto en conocimiento del obligado al pago por notificación judicial, es decir, se requiere de una gestión preparatoria para que adquiera fuerza ejecutiva. Una vez notificado al deudor, puede este objetarlo por las causas señaladas en la ley, esto es, alegar en el acto de notificación, o dentro de tercero día a contar de ella, la falsificación material de la factura o guía de despacho o del recibo de las mercaderías o de los servicios prestados o la falta de entrega de las mercaderías o de la prestación de los servicios. Esta impugnación se debe tramitar como incidente, y en contra de la resolución que la deniega procede el recurso de apelación en el solo efecto devolutivo.

El cumplimiento de todos los requisitos que debe reunir la factura para que tenga título ejecutivo demuestra que es un título de crédito causado y no abstracto, como por ejemplo la letra de cambio.

No obstante lo indicado, la Ley No 20.323 agregó un inciso nuevo al artículo $3^{\circ}$ de la Ley No 19.983, disponiendo: "Serán inoponibles a los cesionarios de una factura irrevocablemente aceptada, las excepciones personales que hubieren podido oponerse a los cedentes de la misma”.

En consideración de lo señalado, el deudor de la factura podrá oponer al titular del crédito todas las excepciones, ya sean personales o reales; en cambio, respecto del cesionario podrá oponer solo las excepciones reales y no aquellas personales. Por lo tanto, no podría oponer la excepción

51 Estas normas están contempladas en el artículo 54 de la Ley del IVA, Decreto Ley No 825 de 1974 y en el artículo 69 letra A, números 1 a 9, de su reglamento, aprobado por Decreto Supremo No 55 de 1977. 
de incumplimiento, puesto que esta excepción es personal, toda vez que tiene su sustento -como su nombre lo refiere- en las relaciones personales de las partes del negocio causal y, como tales, podrían alegarse exitosamente solo en contra del acreedor del contrato que, a su vez, es el dueńo de la factura, precisamente derivado de la situación peculiar en que se encuentra el acreedor en relación con el deudor. Esta excepción se basa en el privativo vínculo existente entre las partes y en las condiciones que dentro de este se hallen, por lo que requieren, entonces, ciertas calidades especiales en el que las alega ${ }^{52}$.

Establecido lo anterior, podemos concluir que es posible ejercitar la excepción de contrato no cumplido solo en contra del titular de la factura y no respecto de su cesionario.

La excepción que deberá oponer el ejecutado es la del artículo 464 No 7 del C.P.C. por carecer de fuerza ejecutiva el título al no ser exigible la obligación, fundado en el artículo 1.552 del C.C.

\section{CONCLUSIONES}

1. La excepción de incumplimiento contractual ejercida como defensa en un juicio ejecutivo, es plenamente aplicable cuando se pretende hacer cumplir obligaciones que emanan de contratos bilaterales de cumplimiento simultáneo. Así, el ejecutado puede oponer la excepción del artículo 464 No 7 del C.P.C. por la falta de exigibilidad, fundado en el artículo 1.552 del C.C.

2. En el ámbito de la contratación vinculada, de obligaciones conexas o coligadas, y en especial en materia de consumo, el ejecutado puede alegar la exceptio non adimpleti contractus o non rite adimpleti contractus si se considera que al prestamista le afecta el incumplimiento del vendedor. Es decir, los efectos del contrato incumplido alcanzan a este tercero al no ser considerado ajeno al contrato de compraventa y, debiendo responder por dicho incumplimiento, permitiendo al ejecutado oponer la excepción de contrato no cumplido.

3. En procedimientos ejecutivos en los cuales los títulos ejecutivos sean letras, pagarés y cheques, al ser documentos abstractos e independientes, ello no permiten poder oponer excepciones personales a los terceros o a personas ajenas a la relación fundamental o negocio que le

52 En este sentido, la sentencia de la Corte Suprema de la primera sala del 26 de noviembre de 2014, rol No 8529-2014. 
dio origen. Respecto de las partes que celebraron el negocio jurídico que generó el acto cambiario, el negocio no reviste el carácter de abstracto e independiente, por lo que entre ellos dicho acto resulta directamente relacionado o vinculado al negocio causal, siendo posible oponer excepciones personales. Por ende, la excepción de incumplimiento contractual es siempre oponible al tenedor del título cuando no ha sido cedido. Con todo, basta que el título circule, para que el consumidor no pueda oponer la exceptio non adimpleti contractus.

4. En razón del artículo $3^{\circ}$ de la Ley No 19.983, el cual fue incorporado por la Ley No 20.323, el deudor de la factura puede oponer al titular del crédito todas las excepciones, ya sean personales o reales; en cambio, respecto del cesionario solo puede oponer las excepciones reales y no aquellas personales. Por lo tanto, no podría oponer la excepción de incumplimiento.

\section{BIBLIOGRAFÍA}

Abeliuk, René (1993) Las obligaciones. Tomo II. Santiago: Editorial Jurídica de Chile.

Aguad, Alejandra (2006) "Algunas reflexiones sobre los efectos del incumplimiento recíproco frente a la acción resolutoria". Revista Chilena de Derecho Privado, N 6, pp. 9-28.

AlCalde, Enrique (2003) "Acción resolutoria y excepción de contrato no cumplido". Actualidad Jurídica, $\mathrm{N}^{\circ} 8$, pp. 68-82.

Alessandri, Arturo (1931) "Nota a sentencia Corte Suprema, 29 de julio de 1931, 2a parte, secc. 1a". Revista de Derecho y Jurisprudencia, t. 8, p. 693.

BaraOna, Jorge (1997) "La exigibilidad de las obligaciones". Revista Chilena de Derecho, vol. 24, No 3, pp. 503-523.

Bernad Mainar, Rafael (2010) "A propósito de una pretendida teoría general de los contratos conexos". Revista Critica de Derecho Inmobiliario, No 720, pp. 1447-1484.

Bozzo, Sebastián (2014) "La excepción de contrato no cumplido adecuadamente o regularmente y su régimen en el derecho civil español". Revista de Derecho de la Pontificia Universidad Católica de Valparaiso, No 42, pp. 83-119.

Bozzo, Sebastián (2015) "Incumplimiento de contratos vinculados en función de consumo y mecanismos de protección en el ordenamiento chileno". Revista de Derecho de la Universidad Católica de Valparaiso, No 45, pp. 39-66. 
Caprile, Bruno (2012) "Algunos problemas ofrecidos por la excepción de contrato no cumplido y, en especial, el de su invocación para atajar la acción resolutoria en el caso de incumplimiento recíproco de los contratantes". Revista de Derecho de la Pontificia Universidad Católica de Valparaiso, No 39.

Casarino, Mario (2009) Manual de Derecho Procesal Civil. Tomo V, Santiago de Chile: Editorial Jurídica.

Claro Solar, Luis (1937) Explicaciones de Derecho Civil Chileno y Comparado. Tomo II, De las obligaciones. Santiago de Chile: Imprenta Nascimento.

Colin, Ambrosio; Capitant, Henri (1924) Curso elemental de derecho civil. Traducción de la última edición francesa por la Redacción de la Revista General de Legislación y Jurisprudencia, con anotaciones al Derecho Civil espańol por De Buen, tomo III. Madrid: Editorial Reus.

Cruz, María (2004) La exceptio non adimpleti contractus. Valencia: Editorial Tirant lo Blanch.

De Cossio, Alfonso (1991) Instituciones de Derecho Civil, Parte General Obligaciones y Contratos. Madrid: Editorial Civitas.

Díez-Picazo, Luis (1996) Fundamentos del Derecho Civil Patrimonial. Vol. II. Madrid: Editorial Civitas.

Domínguez Águila, Ramón (1983) "Los terceros y el contrato". Revista de Derecho de la Universidad de Concepción, No 51, pp. 151-165.

Elgueta, Augusto (1942) La resolución y el incumplimiento reciproco. Santiago: Memoria de Licenciatura, Universidad de Chile.

Espinosa, Raúl (2003) Manual de Procedimiento civil, El juicio ejecutivo. Santiago de Chile: Editorial Jurídica

Esteban, Ignacio (2012) "Alcance de la excepción de incumplimiento del negocio causal en el juicio cambiario". Actualidad Civil, $\mathrm{N}^{\circ} 3$, pp. 269-278.

Fueyo, Fernando (1992) Cumplimiento e Incumplimiento de las obligaciones. Santiago de Chile: Editorial Jurídica de Chile.

Gruss, Guillermo (1998) Juicio Ejecutivo. Tomo I. Santiago de Chile: Editorial Jurídica La Ley.

Henríquez Herrera, Ian (2012) "Para una delimitación del efecto expansivo de los contratos. Comentario a la sentencia de la Corte Suprema de 25 de enero de 2011 Casación en el fondo Rol No 3738-2009". Revista Chilena de Derecho, vol. 39, No 2, pp. 513-522.

Larroumet, Christian (1998) Responsabilidad civil contractual. Algunos temas modernos. Santiago de Chile: Editorial Jurídica de Chile.

López FríAs, Ana (1994) Los contratos conexos. Barcelona: Bosch. 
López Santa María, Jorge (1998) "Las cadenas de contratos o contratos coligados". Revista de Derecho de la Universidad Católica de Valparaiso, No 19, pp.159-166.

López Santa María, Jorge (2005) Los contratos. Tomo II. Santiago de Chile: Editorial Jurídica de Chile.

Marín López, Manuel Jesús (2014) Comentarios a la Ley de Contratos de Crédito al Consumo. Pamplona: Aranzadi.

Marín López, Manuel Jesús (2003) "Dictamen jurídico sobre el caso de English Opening School: crédito al consumo, cesión de créditos y contratos vinculados". Revista Crítica de Derecho Inmobiliario, vol. 79, No 677, pp. 1735-1794.

Mejías Alonzo, Claudia (2013) "La excepción de contrato no cumplido y su consagración en el código civil chileno". Revista Chilena de Derecho, vol. 40, N 2, pp. 389-412.

Mejías Alonzo, Claudia (2014) "La excepción de contrato no cumplido, un análisis de su aplicación en la jurisprudencia nacional reciente y en la doctrina". Revista de Derecho Universidad Católica del Norte, Año $21 \mathrm{~N}^{\circ} 1$, pp. 111-156.

Messineo, Francesco (1952) Doctrina General del Contrato. Buenos Aires: Ediciones Jurídicas Europa-América.

Ogayar y Ayllón, Tomás (1983) Efectos que produce la obligación bilateral: Doctrina jurisprudencial sobre los articulos 1124 y 1504 del Código Civil. Pamplona: Editorial Aranzadi.

Peiteado, Pilar (2004) "La exceptio non rite adimpleti contractus en la oposición al juicio cambiario" (Comentario a la Sentencia 518/2003, de 24 de noviembre, de la Audiencia Provincial de Santa Cruz de Tenerife). Revista de Derecho Bancario y Bursátil, año 23, No 95, pp. 235-246.

PeÑaIlillo, Daniel (2003) Obligaciones. Teoría general y clasificaciones. La resolución por incumplimiento. Santiago de Chile: Editorial Jurídica.

Pizarro, Carlos (2005) "La excepción por incumplimiento contractual en el derecho civil chileno", en AA.VV., Estudios de Derecho Civil: Código $y$ dogmática en el Sesquicentenario de la promulgación del Código Civil (Jornadas Nacionales de Derecho Civil, Valdivia, abril de 2005). Santiago de Chile: Editorial LexisNexis, pp. 324-333.

Pizarro, Carlos (2005) "La interdependencia de contratos que forman un mismo grupo contractual en el derecho francés". Revista Estudios Socio-Jurídicos, No 7, pp. 66-74.

Pizarro, Carlos (2007) "El efecto relativo de los contratos: partes y terceros". El Código Civil de Chile (1885-2005), Editor: Alejandro Guzmán Brito. Santiago de Chile: Editorial LexisNexis. 
Planiol, Marcel; Ripert, Georges (1940) Tratado Práctico de Derecho Civil Francés, Las obligaciones, tomo VI (trad. Mario Díaz Cruz). La Habana: Editorial Cultural.

Prado Puga, Arturo (2016) "Alcance jurídico de la factura como título de circulación mercantil". Revista de Derecho de la Pontificia Universidad Católica de Valparaíso No 46, p. 170

Puelma Accorsi, Álvaro (1999) Letra de Cambio y pagaré en la Ley 18.092. Santiago de Chile: Editorial Jurídica de Chile.

Quezada, José (2012) Proceso ejecutivo. Santiago de Chile: Editorial Librotecnia.

Ramírez, Fernando (1962) La excepción de contrato no cumplido en el juicio ejecutivo. Memoria de Prueba para optar al Grado de Licenciado en Ciencias Jurídicas y Sociales de la Universidad de Chile. Santiago de Chile: Editorial Universitaria.

Rivera Restrepo, José (2011) "Una mirada a la doctrina de la causa y sus distintas versiones en el código civil chileno". Revista de Derecho de la Universidad Católica del Norte, Año 18, № 2, pp. 305-346.

Sandoval, Rircardo (2007) Derecho Comercial. Tomo II. Santiago de Chile: Editorial Jurídica.

Segui, Adela (2001) Teoría de los contratos conexos. Alguna de sus aplicaciones. En Instituciones de Derecho Privado - Contratación Contemporánea, dirigida por Alterini, Atilio Aníbal; De Los Mozos, José Luis; Soto, Carlos Alberto (editores). Bogotá: Editorial Temis S.A., t. II.

Somarriva, Manuel (1939) Las obligaciones y los contratos ante la jurisprudencia. Santiago de Chile: Editorial Nascimento.

Traviesas, Miguel (1929) "Obligaciones Recíprocas". Revista de Derecho Privado, $\mathrm{N}^{\circ} 7$, pp. 273-287.

Ubilla Grandi, Luis Eugenio (1995) Teoría General de la Letra de Cambio y Pagaré en la Ley 18.092. Santiago de Chile: Editorial Jurídica de Chile.

Vargas Vargas, Manuel (1998) Nueva Ley sobre Letras de Cambio y Pagarés. Santiago de Chile: Editorial Jurídica de Chile.

Vergara Bezanilla, José Pablo (2013) "La inoponibilidad de las excepciones en la cesión de créditos expresados en facturas". Revista de Derecho, No 30.

Vial del Río, Víctor (2003) Teoría General del Acto Jurídico. Santiago de Chile: Editorial Jurídica.

VIdal, Álvaro (2008) "El incumplimiento resolutorio en el Código Civil, condiciones de procedencia de la resolución por incumplimiento". En AA.VV., Estudios de Derecho Civil IV, Jornadas Nacionales de Derecho 
Civil Olmué. Santiago de Chile: Editorial LegalPublishing, pp. 349368.

VIdal, Álvaro (2006) "El efecto absoluto de los contratos". Revista Chilena de Derecho Privado, No 6, pp. 51-86.

Yúsari KhaliliyeH, Tarek (2012) Incumplimiento Recíproco y Remedios Contractuales. Santiago de Chile: Editorial LegalPublishing.

\section{JURISPRUDENCIA CITADA}

Corte Suprema. 26 de noviembre de 2014. Rol N ${ }^{\circ}$ 8529-2014. Disponible en: basejurisprudencial.poderjudicial.cl [fecha de visita: 1 de septiembre de 2016].

Corte de Apelaciones de Santiago de Chile. 17 de agosto de 1992. Sin rol. En Revista de Derecho y Jurisprudencia, T. LXXXIX, $\mathrm{N}^{\circ} 2$, segunda parte, sección segunda, pp. 124-125.

Corte de Apelaciones de Santiago de Chile. 11 de noviembre de 2013. Rol No 7152-2012. Disponible en: basejurisprudencial. poderjudicial.cl [fecha de visita: 1 de septiembre de 2016].

Tribunal Supremo Español. 4 de abril de 2011. ROJ STS 2015/2011. Disponible en: www.poderjudicial.es/search [fecha de visita: 1 de septiembre de 2016]. 